\title{
Obtaining and Corrosion Performance of Composite Zinc Coatings with Incorporated Carbon Spheres
}

\author{
Nelly Boshkova ${ }^{1}$, Kamelia Kamburova ${ }^{1}$, Nikola Koprinarov ${ }^{2}$, Mariana Konstantinova ${ }^{2}$, \\ Nikolai Boshkov ${ }^{1, *}$ and Tsetska Radeva ${ }^{1}$ \\ 1 Institute of Physical Chemistry, Bulgarian Academy of Sciences, 1113 Sofia, Bulgaria; \\ nelly.boshkova@ipc.bas.bg (N.B.); kamelia@ipc.bas.bg (K.K.); radeva@ipc.bas.bg (T.R.) \\ 2 Central Laboratory of Solar Energy and New Energy Sources, Bulgarian Academy of Sciences, \\ 1113 Sofia, Bulgaria; koprin1@abv.bg (N.K.); konstantinova@abv.bg (M.K.) \\ * Correspondence: NBoshkov@ipc.bas.bg
}

Received: 20 June 2020; Accepted: 8 July 2020; Published: 11 July 2020

\begin{abstract}
The present work describes one possible way to prepare a stable aqueous suspension of carbon sphere particles with a positive charge that is suitable for simultaneous electrodeposition with zinc on steel substrate. In order to stabilize the suspension against aggregation, tri-block amphiphilic copolymer Pluronic F127, which is commercially available, was adsorbed on the surface of carbon sphere particles. This polymer contained poly (ethylene oxide) blocks as hydrophilic segments and poly (propylene oxide) blocks as the hydrophobic part. Scanning electron microscopy and visual observations confirmed the stability of the obtained suspension. The carbon sphere particles were embedded into the zinc coating by the co-electrodeposition process. The surface morphology of the composite coating was investigated using scanning electron microscopy. The influence of the carbon spheres on the cathodic and anodic processes was evaluated with cyclic voltammetry studies. The electrochemical investigations were realized in a model corrosion medium $(5 \% \mathrm{NaCl}$ solution with $\mathrm{pH}$ 6.7) by application of selected methods such as polarization resistance, potentiodynamic polarization, and electrochemical impedance spectroscopy, which revealed higher protective ability of the composite coating against corrosion in an aggressive environment.
\end{abstract}

Keywords: composite coating; zinc; carbon spheres; corrosion; suspension stabilization

\section{Introduction}

Zinc is generally applied to ensure galvanic protection against corrosion of steel as it exhibits an anodic character with respect to iron and dissolves first in an aggressive environment. Dissolution of this metal in a neutral corrosion medium containing $\mathrm{Cl}^{-}$-ions leads to the creation of a layer of corrosion products on the surface. These products are characterized by a low solubility value (zinc oxides, hydroxides, hydroxide chlorides, etc.) and impede the penetration of corrosive agents inside the underlying metal [1-3]. Incorporation of nano- or microparticles, such as $\mathrm{SiO}_{2}, \mathrm{TiO}_{2}, \mathrm{ZrO}_{2}$, polytetrafluorethylene (PTFE), and polyaniline- $\mathrm{SiO}_{2}\left(\mathrm{PANI}-\mathrm{SiO}_{2}\right)$ particles, enhances the protective characteristics of the ordinary zinc coatings [4-8]. The reason for this phenomenon seems to be the appearance of a mixed layer that simultaneously contains the corrosion products and the incorporated particles. This mixed layer demonstrates better properties as a result of synergistic effects, which cannot be achieved by each component separately. Composite zinc coating has also been electrodeposited on mild steel using dispersed nanosized $(5-10 \mathrm{~nm})$ carbon black particles [9].

There are several papers that have studied the application of carbon nanotubes (CNTs) in composite zinc coatings on steel [10-12]. However, the results about CNTs role in corrosion protection of steel are to a certain degree contradictory. The electrochemical studies by Praveen et al. revealed higher 
resistance of the composite zinc coating to corrosion in 3.5\% $\mathrm{NaCl}$ solution [7]. The incorporation of CNTs in the zinc coating was found to shift the potential toward a more positive direction, which means that the composite coating possesses more reducing power and the dissolution of zinc is slowed down. The addition of CNTs into the zinc coating was also suggested to provide a physical barrier to the corrosion medium as the carbon nanotubes can fill the microholes of the metal surface, which are usually active sites for metal dissolution. In contrast, the study by Peshova et al. showed about $25 \%$ lower corrosion resistance of a composite zinc coating containing CNTs [13]. The appearance of galvanic couples as a result of inhomogeneous distribution of the CNTs into the zinc matrix was suggested as one reason for the accelerated corrosion attack [13].

Generally, ionic and non-ionic surfactants are used in electroplating solutions to improve the distribution of the CNTs in the metal matrix. As CNTs are strongly hydrophobic, they are inclined to aggregate if dispersed in water. For that reason, the preparation of stable CNTs dispersions in water is of great significance and still a challenge for their application as reinforcing particles in composite coatings. The surfactant molecules may be adsorbed on the CNT surface with their hydrophobic parts next to the surface and the hydrophilic parts facing outward in the solution. Different surfactants may affect the properties of the composite coatings in different ways [14-16]. For example, the addition of an anionic surfactant in the depositing bath was found to increase the corrosion resistance of a Ni-CNT composite coating, in contrast to the addition of a cationic surfactant [11]. On the other hand, Praveen et al. used a cationic surfactant for the preparation of a Zn-CNTs composite coating, which presented better anticorrosion effect compared to the standard zinc coating [7].

Non-ionic surface modifications were developed to increase the dispersion of the carbon particles despite the relatively weak interaction between their surfaces and the modifiers (providing steric stabilization of suspensions) [17]. Amphiphilic block copolymers, which can form micelles in the selective solvents, have been used to disperse the carbon particles. For example, a series of nonylphenol ethoxylates, having a constant hydrophobic group composition and varying numbers of ethylene oxide groups, were shown to stabilize carbon black suspension against aggregation [18]. A polystyrene-polyethylene oxide copolymer was also found to increase the stability of carbon black particles in water [19]. The amount and structure of PEO-PPO-PEO (PEO: poly(ethylene oxide), PPO: poly(propylene oxide)) block copolymers (Pluronics) adsorbed onto hydrophobic carbon black nanoparticles in water has also been studied $[15,20]$. The effect of surfactants on dispersion of CNTs and carbon black particles was recognized due to decrease in the particle sizes.

The aim of this investigation was the fabrication of homogeneous zinc-carbon composite coating from a slightly acidic sulfate solution containing well dispersed microsized carbon spheres (CSp). The latter have properties similar to those of graphite [21]. The availability of relatively easy and efficient methods for carbon sphere preparation was one reason for their application as additives in the composite zinc-carbon coating. Our interest in them also resulted from the uniformity, hydrophobic surfaces, and chemical inertness of the spheres. The composite coating was electrodeposited on mild steel, applying the non-ionic polymer Pluronic F127 as a dispersing agent for the carbon particles. We demonstrated the feasibility of the carbon spheres for enhancing the protective efficiency against corrosion of ordinary zinc coating on steel.

\section{Experimental Section}

\subsection{Materials and Methods}

Carbon spheres (CSp) were synthesized by pyrolitic decomposition of xylene in an iron container according the procedure described in [22]. The container was hermetically closed by a spherical steel cover with a pressure of $100 \mathrm{~Pa}$. The heating of the container was done in a furnace with the temperature rising at a rate of $20^{\circ} \mathrm{C} / \mathrm{min}$. The synthesis continued for $15 \mathrm{~min}$ at $600^{\circ} \mathrm{C} / \mathrm{min}$ followed by cooling at a rate of $30^{\circ} \mathrm{C} / \mathrm{min}$. For graphitization, sphere particles thus obtained were heated in vacuum at $2000{ }^{\circ} \mathrm{C}$ for $15 \mathrm{~min}$. Synthesis in a closed space resulted in the formation of particles with diameters 
ranging from 1 to $12 \mu \mathrm{m}$ [22]. Figure 1 shows carbon spheres before and after their graphitization. The average diameter of the carbon spheres used in the presented study is approximately $5.4 \pm 1.2 \mu \mathrm{m}$, determined by scanning electron microscopy.

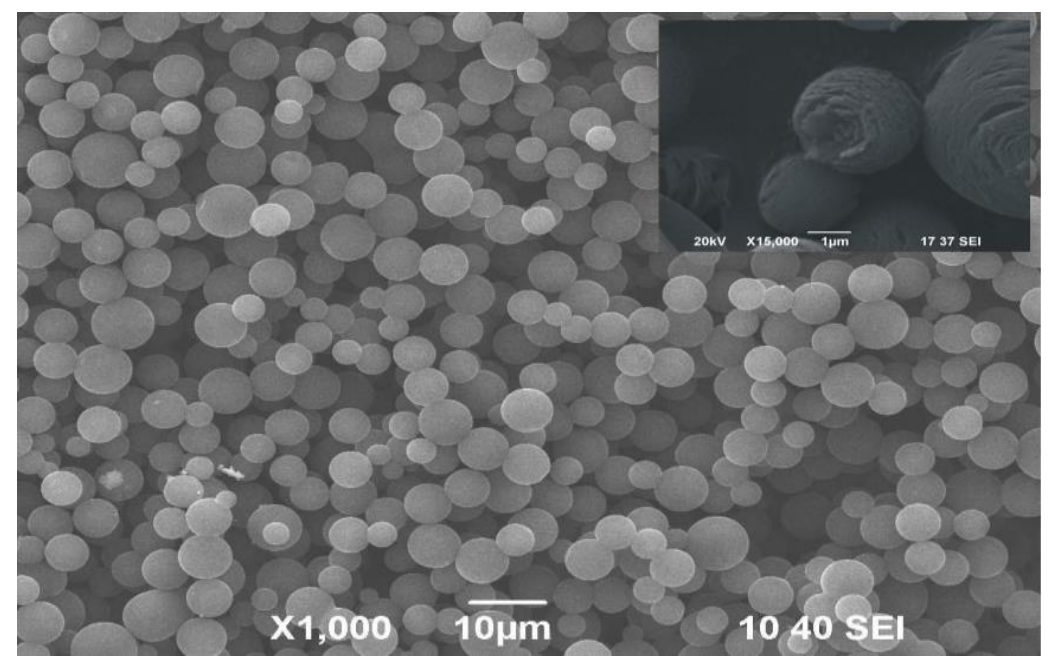

Figure 1. SEM images of carbon spheres before and after (inset) their graphitization.

Commercially available non-ionic polymer $\mathrm{PEO}_{100} \mathrm{PPO}_{65} \mathrm{PEO}_{100}$ of $\mathrm{M}_{\mathrm{w}}=12.6 \mathrm{kDa}$, which is known as Pluronic ${ }^{\circledR}$ F127, was delivered by Sigma-Aldrich (Darmstadt, Germany). Its critical micelle concentration is $7 \mathrm{~g} / \mathrm{L}$ at $25^{\circ} \mathrm{C}$ [15]. Analytical grade chemicals $\mathrm{ZnSO}_{4} \cdot 7 \mathrm{H}_{2} \mathrm{O}, \mathrm{NH}_{4} \mathrm{Cl}_{1} \mathrm{H}_{3} \mathrm{BO}_{3}, \mathrm{HCl}$, $\mathrm{NaOH}$, and $\mathrm{NaCl}$ are also supplied by Sigma-Aldrich (Darmstadt, Germany).

\subsection{Polymer Stabilizaion of Carbon Sphere Suspension}

Carbon sphere suspension was prepared by a dispersion of $0.1 \mathrm{~g}$ particles in $1 \mathrm{~L}$ distilled water at $30 \mathrm{~min}$ sonication. The electrophoretic mobility of the carbon spheres was followed as a function of $\mathrm{pH}$ from 3.0 to 6.0 to determine the $\zeta$-potential values, which are considered to be the necessary minimum to obtain stable suspension [23]. For stabilization of the carbon sphere suspension against aggregation during co-electrodeposition with zinc on the steel sample, Pluronic F127 solutions with concentrations varied from 0.9 to $20 \mathrm{~g} / \mathrm{L}(0.9,1,2,3,4,5,7,10,15$, and $20 \mathrm{~g} / \mathrm{L})$ were added to the suspensions of $0.1 \mathrm{~g} / \mathrm{L}$ concentration and sonicated for 3, 5, 20, and $30 \mathrm{~min}$. Visual stabilization of the suspension was registered at concentrations higher than $5 \mathrm{~g} / \mathrm{L}$.

\subsection{Electrophoretic Mobility of Carbon Spheres}

The electrophoretic mobility of the particles $\left(U_{e}\right)$ was measured as a function of $\mathrm{pH}$ by application of the Rank Brothers Mark II device. The measurements were repeatable and the error was less than $10 \%$. Using Smoluchowski's relationship:

$$
\zeta=U_{e} \eta / \varepsilon
$$

where $\eta$ and $\varepsilon$ are the viscosity and dielectric constant of the medium, respectively. The $\zeta$-potential values of the particles were calculated from the electrophoretic mobility data.

\subsection{Electrodeposition of Composite Coating on Steel}

A stable suspension containing carbon spheres with concentrations of 0.1 and $7 \mathrm{~g} / \mathrm{L}$ Pluronic F127 (sonicated for $30 \mathrm{~min}$ ) was selected for electrodeposition with zinc at $\mathrm{pH}$ 4.5-5.0. The slightly acidic zinc electrolyte solution contained $150 \mathrm{~g} / \mathrm{L} \mathrm{ZnSO} 4 \cdot 7 \mathrm{H}_{2} \mathrm{O}, 30 \mathrm{~g} / \mathrm{L} \mathrm{NH} \mathrm{Cl}_{4} \mathrm{Cl}$, and $30 \mathrm{~g} / \mathrm{L} \mathrm{H}_{3} \mathrm{BO}_{3}$. A glass cell of $300 \mathrm{~mL}$ volume was used for the electrodeposition process. The latter was carried out in a 
room temperature of about $25^{\circ} \mathrm{C}$, with a current density of $2 \mathrm{~A} / \mathrm{dm}^{2}$ and an application of soluble metallurgical zinc anodes [2]. The concentration of the CSp in the electrolyte to obtain the composite coating was $5 \times 10^{-2} \mathrm{~g} / \mathrm{L}$. Ordinary zinc and composite zinc coatings were electrodeposited on low carbon steel samples with sizes $20 \times 10 \times 1 \mathrm{~mm}$ and composition as follows (wt.\%): C-0.05-0.12; $\mathrm{S} \leq 0.04 ; \mathrm{P} \leq 0.35 ; \mathrm{Mn}-0.25-0.5 ; \mathrm{Cr} \leq 0.1 ; \mathrm{Si} \leq 0.03 ; \mathrm{Ni} \leq 0.3 ; \mathrm{Cu} \leq 0.3 ; \mathrm{As} \leq 0.08$; Fe-balance. The thickness of the obtained coatings was calculated to be $\sim 11 \mu \mathrm{m}$. The coatings were dried in air before their corrosion behavior was tested.

\subsection{Methods for Corrosion Characterization of the Coatings}

Corrosion resistance of the coatings was evaluated by several electrochemical methods such as: polarization resistance (Rp); potentiodynamic polarization curves (PD); electrochemical impedance spectroscopy (EIS); and cyclic voltammetry polarization (CVA). All the methods have been realized with computerized PAR unit VersaStat 4 (Princeton Applied Research, Oak Ridge, TN, USA). The investigations have been realized by application of a three-electrode glass cell with a volume of $300 \mathrm{~mL}$. The reference electrode was saturated calomel electrode (SCE), while a platinum plate was recognized as a counter. The working electrode was the tested sample (zinc or composite coating) for $\mathrm{Rp}, \mathrm{PD}$, and EIS. For CVA investigations, a Pt-rod with an area of $0.16 \mathrm{~cm}^{2}$ was applied. The principles and features of the methods used are described in more detail elsewhere $[8,13]$.

\subsection{Surface and Composition of the Coatings}

The zinc and composite coating surfaces were studied with a scanning electron microscope (JEOL JSM 6390 and INCA Energy 350 unit, Tokyo, Japan). The XRD method was applied in order to register the chemical composition of the samples before and after their corrosion treatment in the model medium by application of Apparatus EMPYREAN (Almelo, The Netherlands). The PANalytical program, Version 3.0d(3.0.4.), (Panalytical B.V., Almelo, The Netherlands was used for data processing.

\subsection{Corrosion Medium and Reproducibility}

The investigations were held in a model corrosion medium of $5 \% \mathrm{NaCl}$ solution at $\mathrm{pH} 6.7$ and at ambient temperature. The reproducibility of the tests is an average of 5 samples per sample type.

\section{Results and Discussion}

\subsection{Stabilization of Carbon Particle Suspension by Addition of Pluronic F127}

Figure 2 shows the variation of $\zeta$-potential values of carbon sphere particles as a function of $\mathrm{pH}$ in the aqueous suspension. The electrokinetic measurements were carried out at a particle concentration of $0.1 \mathrm{~g} / \mathrm{L}$. It can be seen that the particles are positively charged at $\mathrm{pH}<3.8$ and negatively charged at the higher $\mathrm{pH}$ values (isoelectric point of the suspension is at $\mathrm{pH} \approx 3.8$ ). This result is similar to those found for the $\zeta$-potential of the carbon nanotubes and carbon black particles [24-26]. Depending on the source, heat treatment, and manufacturing process of the particles, different isoelectric point values are cited in the literature $[27,28]$.

In aqueous media $(\mathrm{pH}>4)$, the carbon sphere surface is negatively charged due to the dissociation of surface $\mathrm{OH}$ - and $\mathrm{COOH}$ - groups resulting from the treatment of the initial material. The $\zeta$-potential of the carbon particles increases with increasing $\mathrm{pH}$ of the suspension as a result of a rise in the degree of dissociation of the weakly acidic surface functional groups. In acidic media $(\mathrm{pH}<4)$, the particles are positively charged because of proton attachment to hydroxyl and carboxyl surface groups. Poor solubility of carbon particles is found around $\mathrm{pH}$ values close to the isoelectric point, which is attributed to the strong van der Waals attraction forces between particles and water. Increased solubility further from the isoelectric point is mainly attributed to the increased number of functional groups at active sites of the carbon particles' surfaces. Electrostatic repulsion between relatively strongly charged particles $(\zeta$-potential $>30 \mathrm{mV})$ is believed to ensure suspension stability far from the isoelectric point [23]. 


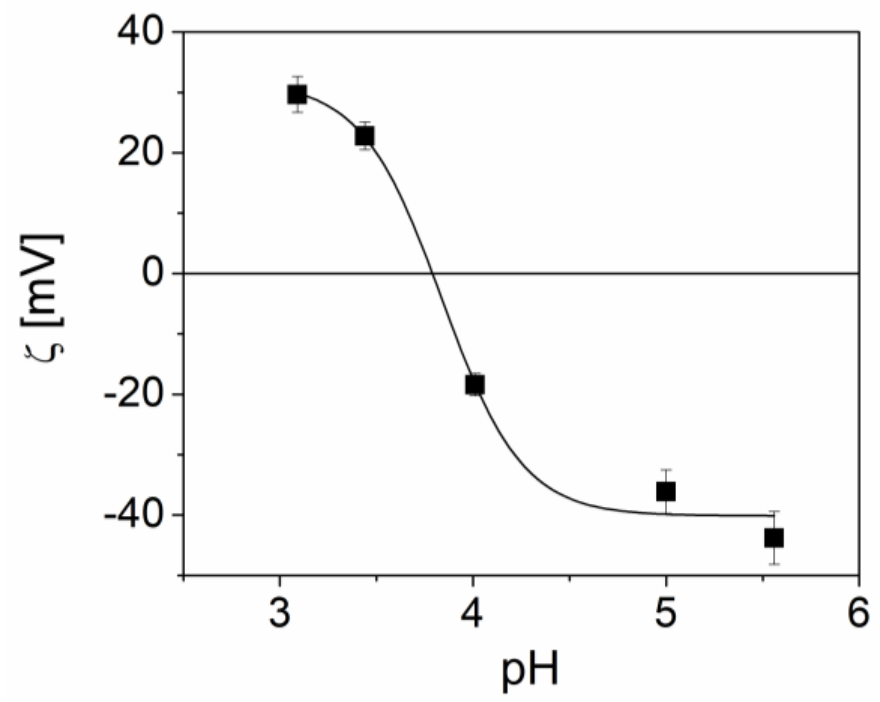

Figure 2. $\mathrm{pH}$ dependence of $\zeta$-potential of carbon sphere particles in a $0.1 \mathrm{~g} / \mathrm{L}$ aqueous suspension.

Co-electrodeposition of zinc and carbon spheres on steel substrate was performed at $\mathrm{pH} 3.25$. The carbon particles are positively charged at this $\mathrm{pH}$ and can be deposited on a cathode (steel) surface. When a stable suspension of carbon particles (with $\zeta$-potential $\approx 30 \mathrm{mV}$ ) was added to the zinc sulfate solution, however, strong aggregation was observed because of the high ion concentration in the zinc sulfate solution $(\geq 1 \mathrm{M})$. To prevent the aggregation, $7 \mathrm{~g} / \mathrm{L}$ Pluronic F127 was added to the stable carbon sphere suspension of $0.1 \mathrm{~g} / \mathrm{L}$ concentration at $\mathrm{pH}$ 6.0. Adsorption of Pluronic F127 micelles seems to be the main reason for stabilization of the suspension. As expected, the particles remained negatively charged after the addition of the non-charged polymer (see Figure 2). However, we found that after mixing of the above suspension with $\mathrm{ZnSO}_{4}$ solution of concentration $1 \mathrm{M}$, the $\mathrm{pH}$ of the mixed system strongly decreased (below pH 3.8), which means that the carbon particles acquired positive surface charge, i.e., they became suitable for electrodeposition on a cathode surface. The carbon particles remained well dispersed in the suspension during the next $24 \mathrm{~h}$.

The used polymer also played the role of a wetting agent needed for the preparation of the uniform composite coating. In addition, entrapment of free PEO-PPO-PEO micelles into a standard zinc coating was found to improve its corrosion resistance $[29,30]$. Coordination bonds between $\mathrm{Zn}^{2+}$ ions and PEO-blocks of the polymer are suggested to be the cause of the electrodeposition of Pluronic F127 micelles on the steel substrate.

\subsection{Morphology of the Zinc-Carbon Sphere Coating}

The surface morphology of the composite ZnCSp coating on steel is presented in Figure 3. The scanning electron image (Figure 3-right) shows that the greater part of the coating is covered by needle-like formations, most probably with a metallic character. This could be a result of changes in the zinc phase orientation during the electrodeposition process in the presence of the particles. Incorporation of the latter into the zinc matrix is better seen from the backscattered part of the image (Figure 3-left). It shows the incorporation of carbon spheres into the composite coating having almost the same size as in the starting suspension (inset in Figure 3). 


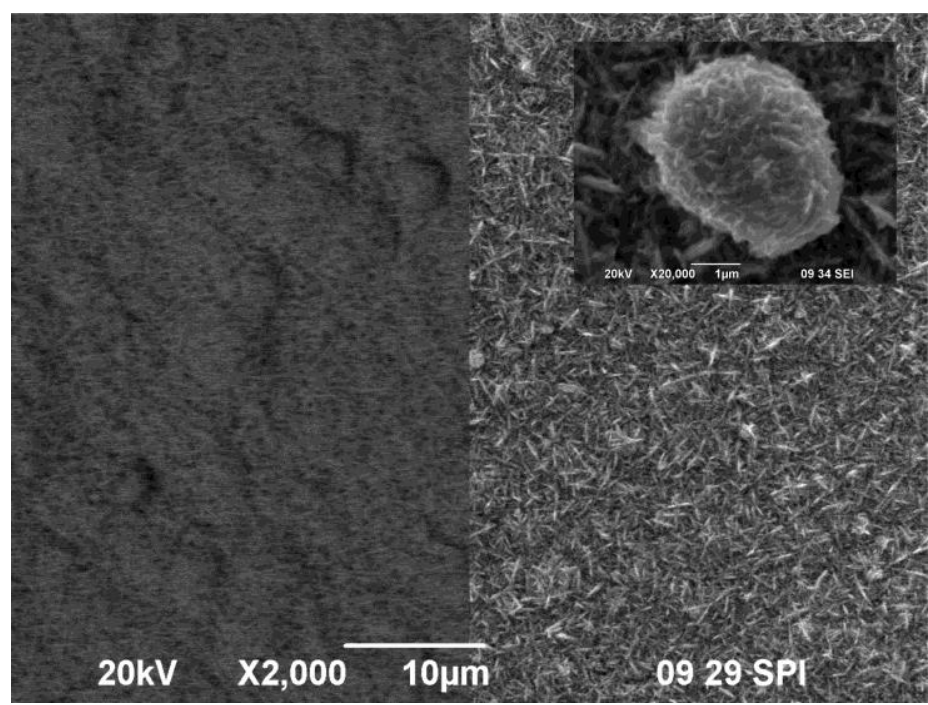

Figure 3. Surface morphology of zinc-carbon sphere coating on steel. Inset: carbon sphere at high magnification.

\subsection{Electrochemical Tests}

\subsubsection{Polarization Resistance Investigations}

The polarization resistance measurements of both coating types-composite ZnCSp and ordinary zinc-during a 60 -days stay in the model $5 \% \mathrm{NaCl}$ solution are presented in Figure 4 . It is obvious that, from the start of the investigation, the Rp values of $\mathrm{ZnCSp}$ sample are still greater in the range of $800 \Omega \mathrm{cm}^{2}$. Thereafter, the polarization resistance of the composite coating increases up to the 15th day, followed by a slight decrease until the 40th day. However, the Rp values of this sample are higher compared to the ordinary zinc throughout the whole testing period. At the end of the investigation, ZnCSp demonstrate an Rp value of $\sim 1750 \Omega \mathrm{cm}^{2}$ and the ordinary zinc coating demonstrates an $\mathrm{Rp}$ value of $\sim 1100 \Omega \mathrm{cm}^{2}$.

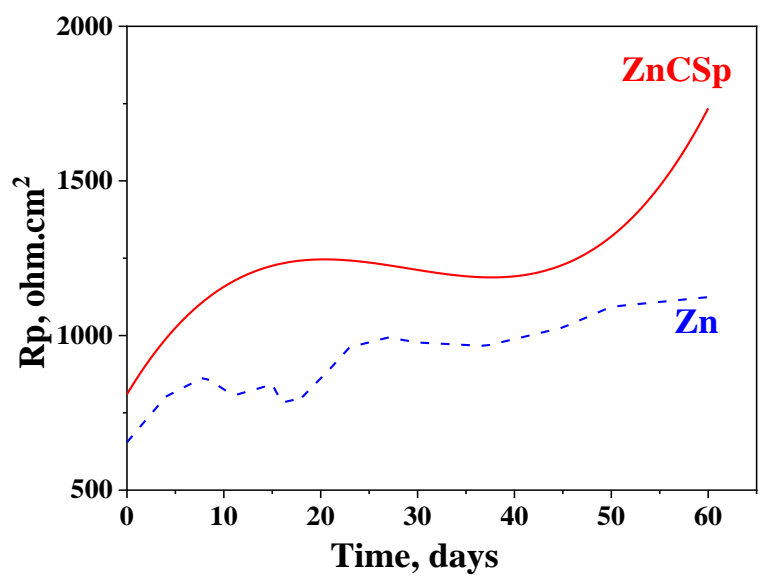

Figure 4. Polarization resistance measurements of $\mathrm{Zn}$ and $\mathrm{ZnCSp}$ coatings.

As discussed elsewhere [8,29], the reason for the behavior of the composite coatings in a neutral corrosive medium seems to be the appearance of a mixed protective layer of zinc corrosion products, the latter also containing the incorporated particles-CSp in our case. Generally, according to SEM, CSp seem to be relatively randomly distributed in the metal matrix and physically hinder (barrier effect) the penetration of the corrosive agents $\left(\mathrm{Cl}^{-}\right.$-ions) deep inside, thus demonstrating additional protective influence. 


\subsubsection{Potentiodynamic (PD) Polarization}

The potentiodynamic polarization curves of the investigated coatings are demonstrated in Figure 5. Ordinary $\mathrm{Zn}$ and composite $\mathrm{ZnCSp}$ coatings practically have very close corrosion potential ( $\mathrm{E}_{\text {corr }}$ ) values: -1.063 and $-1.074 \mathrm{~V}$, respectively. Generally, such an observation could be assumed to be due to the predominantly metallic character of both samples.

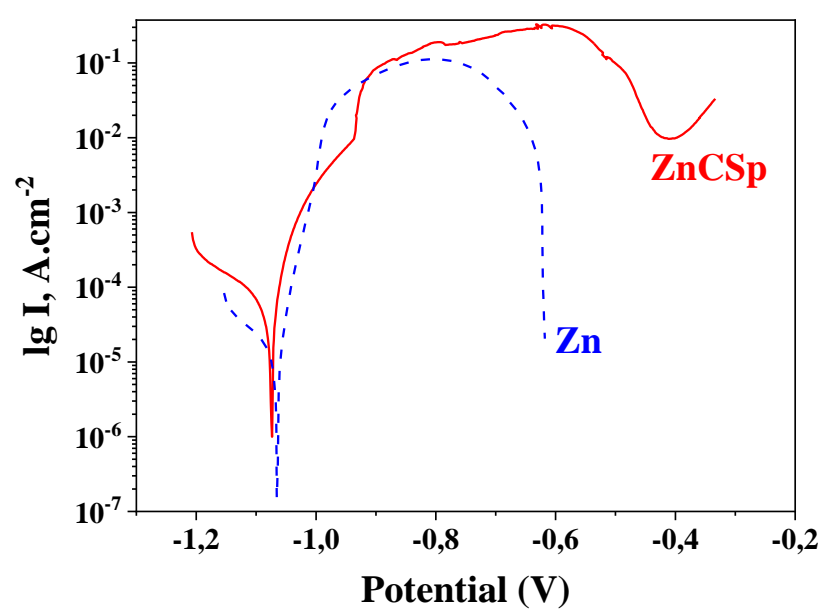

Figure 5. Potentiodynamic polarization curves of Zn and ZnCSp coatings.

Somewhat unexpectedly, the corrosion current densities $\left(\mathrm{I}_{\text {corr }}\right)$ of the ordinary zinc coating are lower $\left(-1.6 \times 10^{-5} \mathrm{~A} / \mathrm{cm}^{2}\right)$ compared to those of the composite $\left(-5.9 \times 10^{-5} \mathrm{~A} / \mathrm{cm}^{2}\right)$, i.e., about 3.7 times lower. The reason for such a phenomenon in conditions of external anodic polarization could be the presence and distribution of CSp in the metal matrix, which will increase the current intensity on the metallic part of the coating compared to the non-metallic one. In addition, the anodic curve of $\mathrm{ZnCSp}$ is characterized by a decreased rate in the potential area between -1 and $-0.95 \mathrm{~V}$ compared to the ordinary $\mathrm{Zn}$. The most probable reason for this could be the appearance of more CSp on the surface (as a result of the selective anodic dissolution of the surrounding zinc), leading to an increased barrier effect.

\subsubsection{Electrochemical Impedance (EIS) Measurements}

The results obtained from the electrochemical impedance spectroscopy for both investigated coatings are shown in Figure 6. It is obvious that the ZnCSp sample distinguishes with greater Rp value (measured on the $\mathrm{X}$ axes) —about $250 \Omega$. For comparison, this parameter for the ordinary $\mathrm{Zn}$ is $\approx 110 \Omega$.

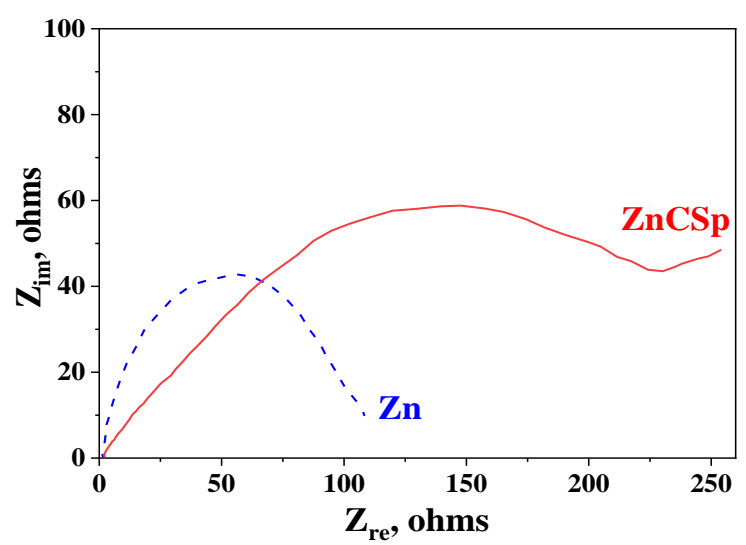

Figure 6. Electrochemical impedance spectroscopy (EIS) measurements of Zn and ZnCSp coatings. 
These results correspond qualitatively to the case of PD curves and polarization resistance and can be explained with the appearance of surface layers of corrosion products, the latter protecting the substrate from the penetration of corrosion agents. Concerning the composite coating, it must be mentioned that the protective layer is "mixed" with CSp particles, which additionally improve the protective action due to the apparent physical barrier effect.

\subsubsection{Cyclic Voltammetry (CVA)}

These experiments were carried out in the starting electrolytes for the electrodeposition of ordinary $\mathrm{Zn}$ and composite ZnCSp coatings-Figure 7. The incorporated CSp particles strongly affect the course of the cathodic and anodic branches of the experimental curves. The electrodeposition of both sample types starts at very close potential values of about $-1.07 \mathrm{~V}$. Nevertheless, the deposition rate of the composite at potential value of $-1.4 \mathrm{~V}$ (vertex potential) is obviously slower $(-0.004 \mathrm{~mA})$ compared to the same parameter of the ordinary zinc, which is $-0.05 \mathrm{~mA}$, i.e., about 12 times lower. Most probably, this effect could be explained by the assumption that CSp particles, being of greater scale compared to zinc ions, will cover a larger cathodic area, thus hindering the electrodeposition of the zinc.

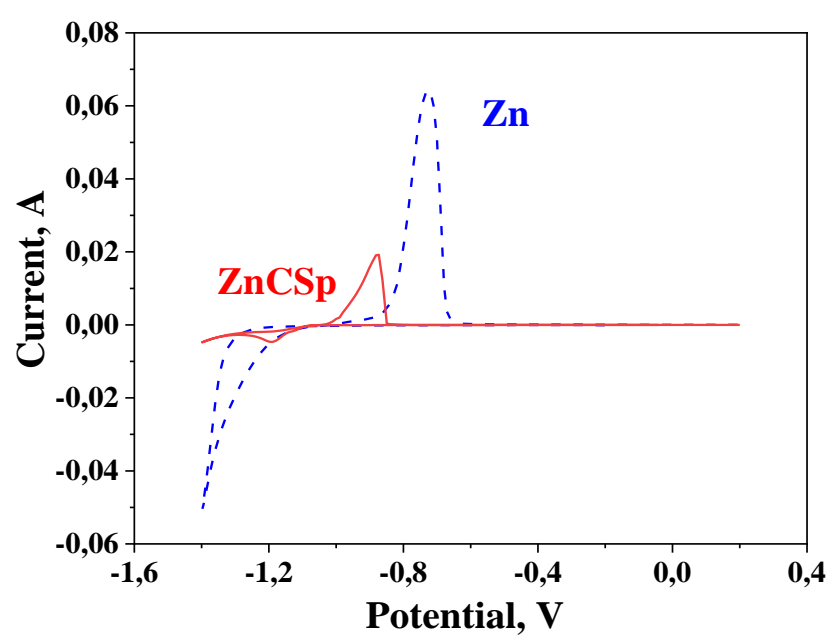

Figure 7. Cyclic voltammetry polarization (CVA) investigations of Zn and ZnCSp coatings.

Generally, the anodic areas of the curves correspond to the cathodic ones in regard to the current values and the quantity of the electrodeposited coatings. However, the anodic dissolution peak of $\mathrm{ZnCSp}$ is placed at a more negative potential value $(-0.88 \mathrm{mV})$ compared to that of the ordinary zinc $(-0.72 \mathrm{~V})$, i.e., this coating will dissolve earlier, producing as a result a mixed layer with CSp to protect the underlying substrate.

\subsubsection{XRD Investigations}

The results from the XRD investigations of ZnCSp coating before (down) and after (middle) corrosion treatment during the 60 days in the model corrosion medium are presented in Figure 8. For comparison, the XRD pattern of ordinary zinc treatment is also presented (up). As is well known from previous investigations, the main reason for the improved corrosion resistance of the $\mathrm{Zn}$-based coatings in such a medium is the appearance of corrosion products with a low product of solubility value - mainly zinc hydroxide chloride (ZHC) $[2,8,29]$. However, in that case, XRD patterns obtained for corrosive treated composite and ordinary $\mathrm{Zn}$ also present additional peaks of other compounds such as zinc hydroxide carbonate $\mathrm{Zn}_{5}(\mathrm{OH})_{6}\left(\mathrm{CO}_{3}\right)_{2}, \mathrm{ZnO}$, and $\mathrm{Zn}(\mathrm{OH})_{2}$, which contribute to the appearance of the protective mixed layer with barrier properties. It is obvious that the amount of corrosion products is greater in the case of the composite coating (better expressed peaks). This observation could be assumed to be a reason 
for the better corrosion resistance of ZnCSp, keeping in mind that the abovementioned compounds will improve the barrier properties of the protective layer.

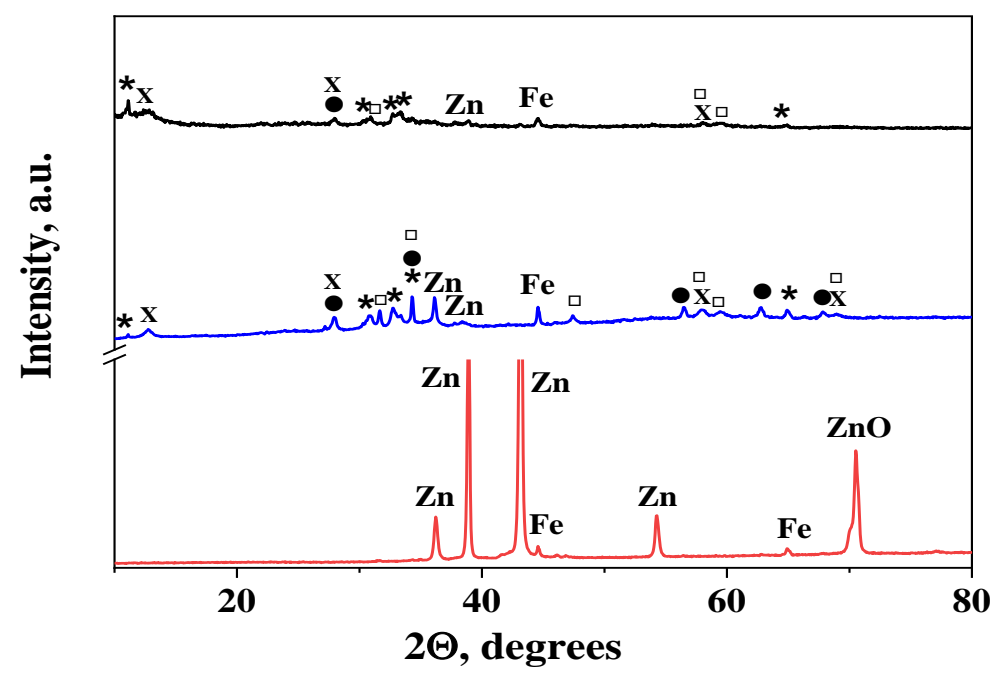

Figure 8. XRD patterns of corrosive treated ordinary $\mathrm{Zn}$ (up) as well as of $\mathrm{ZnCSp}$ coating before (down) and after (middle) corrosion treatment. *- $\mathrm{Zn}_{5}(\mathrm{OH})_{8} \mathrm{Cl}_{2} \cdot \mathrm{H}_{2} \mathrm{O} ; \bullet-\mathrm{Zn}(\mathrm{OH})_{2} ; \square-\mathrm{ZnO} ; \mathrm{x}-\mathrm{Zn}_{5}(\mathrm{OH})_{6}\left(\mathrm{CO}_{3}\right)_{2}$.

\section{Conclusions}

These investigations demonstrate the effect of the incorporation of modified carbon sphere particles on the protective properties and corrosion characteristics of composite zinc coating with incorporated carbon spheres on steel substrate. The main results can be summarized as follows:

(1) Steric stabilization of a colloidal suspension of positively charged CSp particles was realized by applying non-ionic amphiphilic tri-block copolymer Pluronic F127 at concentrations of $7 \mathrm{~g} / \mathrm{L}$. SEM investigations clearly demonstrate the uniform distribution of CSp particles in the metallic zinc matrix of the composite coating.

(2) The Rp, PD, and EIS methods clearly presented the positive effect of CSp particles on the protective properties of the composite for 60 days and at conditions of external polarization.

(3) The main reason for the improved corrosion resistance and protective ability in that medium seems to be the forming of a mixed layer, the latter simultaneously containing zinc corrosion products and CSp particles, which leads to the appearance of an additional physical barrier against the penetration of the corrosive agents deep inside.

Author Contributions: Conceptualization, T.R. and N.B. (Nikolai Boshkov); Data curation, N.B. (Nelly Boshkova), K.K., N.K., and M.K.; Formal analysis, K.K. and N.B. (Nelly Boshkova); Funding acquisition, N.B. (Nikolai Boshkov) and T.R.; Investigation, N.B. (Nelly Boshkova) and K.K.; Methodology, N.B. (Nelly Boshkova), K.K., N.K., M.K., and T.R.; Writing-review \& editing, N.B. (Nikolai Boshkov) and T.R. All authors have read and agreed to the published version of the manuscript.

Funding: This research was funded by Bulgarian Fund for Scientific Research, Grant Number DN 09/6 “Design of innovative metal and hybrid zinc coatings for improvement of steel corrosion protection".

Conflicts of Interest: The authors declare no conflict of interest. The funders had no role in the design of the study, in the collection, analyses, or interpretation of data; in the writing of the manuscript, or in the decision to publish the results.

\section{References}

1. Brenner, A. Electrodeposition of Alloys. Principles and Practice; Academic Press: New York, NY, USA, 1963; pp. 123-152. 
2. Boshkov, N. Galvanic Zn-Mn alloys-electrodeposition, phase composition, corrosion behavior and protective ability. Surf. Coat. Technol. 2003, 172, 217-226. [CrossRef]

3. Li, M.; Luo, S.; Qian, Y.; Zhang, W.; Jiang, L.; Shen, J. Effect of additives on electrodeposition of nanocrystalline zinc from acidic sulfate solutions. J. Electrochem. Soc. 2007, 154, D567-D571. [CrossRef]

4. Tuaweri, T.J.; Adigio, E.M.; Jombo, P.P. Influence of process parameters on the cathode current efficiency of $\mathrm{Zn} / \mathrm{SiO}_{2}$ electrodeposition. Int. J. Mechan. Eng. Appl. 2013, 1, 93-99. [CrossRef]

5. Fayomi, O.S.I.; Popoola, A.P.I.; Loto, C.A. Tribo-mechanical investigation and anti-corrosion properties of $\mathrm{Zn}-\mathrm{TiO}_{2}$ thin film composite coatings from electrolytic chloride bath. Int. J. Electroch. Sci. 2014, 9, 3885-3903.

6. Vathsala, K.; Venkatesha, T.V. $\mathrm{Zn}-\mathrm{ZrO}_{2}$ nanocomposite coatings: Electrodeposition and evaluation of corrosion resistance. Appl. Surf. Sci. 2011, 257, 8929-8936. [CrossRef]

7. Praveen, B.M.; Venkatesha, T.V.; Arthoba, N.Y.; Prashantha, K. Corrosion studies of carbon nanotubes-Zn composite coating. Surf. Coat. Technol. 2007, 201, 5836-5842. [CrossRef]

8. Kamburova, K.; Boshkova, N.; Tabakova, N.; Boshkov, N.; Radeva, T. Application of polymeric modified polyaniline-silica particles for improved corrosion resistance of hybrid zinc coatings. Colloids Surf. A Physicochem. Eng. Aspects 2020, 592, 124546. [CrossRef]

9. Praveen, B.M.; Venkatesha, T.V. Generation and corrosion behavior of Zn-nano sized carbon black composite coating. Int. J. Electrochem. Sci. 2009, 4, 258-266.

10. Chen, X.H.; Chen, C.S.; Xiao, H.N.; Cheng, F.Q.; Zhang, G.; Yi, G.J. Corrosion behavior of carbon nanotubes-Ni composite coating. Surf. Coat. Technol. 2005, 191, 351-356. [CrossRef]

11. Guo, C.; Zuo, Y.; Zhao, X.; Zhao, J.; Xiong, J. Effects of surfactants on electrodeposition of nickel-carbon nanotubes composite coatings. Surf. Coat. Technol. 2008, 202, 3385-3390. [CrossRef]

12. Bakshi, S.R.; Lahiri, D.; Agarwal, A. Carbon nanotube reinforced metal matrix composites-a review. Intern. Mater. Rev. 2010, 55, 41-64. [CrossRef]

13. Peshova, M.; Bachvarov, V.; Vitkova, S.; Atanasova, G.; Boshkov, N. Electrodeposited zinc composite coatings with embedded carbon nanotubes—advanced composite materials for better corrosion protection. Trans. IMF 2018, 96, 324-331. [CrossRef]

14. Padovani, G.C.; Petry, R.; Holanda, C.A.; Sousa, F.A.; Saboia, V.M.; Silva, C.A.; Paschoal, A.R.; Souza Filho, A.G.; Paula, A.J. Mechanisms of colloidal stabilization of oxidized nanocarbons in the presence of polymers: Obtaining highly stable colloids in physiological media. J. Phys. Chem. C 2015, 119, 18741-18752. [CrossRef]

15. Lin, Y.; Alexandridis, P. Temperature-dependent adsorption of Pluronic F127 block copolymers onto carbon black particles dispersed in aqueous media. J. Phys. Chem. B 2002, 106, 10834-10844. [CrossRef]

16. Bodratti, A.M.; Wu, J.; Jahan, R.; Sarkar, B.; Tsianou, M.; Alexandridis, P. Mono-and di-valent salts as modifiers of PEO-PPO-PEO block copolymer interactions with silica nanoparticles in aqueous dispersions. J. Disp. Sci. Technol. 2015, 36, 1806-1815. [CrossRef]

17. Wang, Z.; Liu, Q.; Zhu, H.; Liu, H.; Chen, Y.; Yang, M. Dispersing multi-walled carbon nanotubes with water-soluble block copolymers and their use as supports for metal nanoparticles. Carbon 2007, 45, 285-292. [CrossRef]

18. Sis, H.; Birinci, M. Effect of nonionic and ionic surfactants on zeta potential and dispersion properties of carbon black powders. Coll. Surf. A: Physicochem. Eng. Aspects 2009, 341, 60-67. [CrossRef]

19. Ridaoui, H.; Jada, A.; Vidal, L.; Donnet, J.-B. Effect of cationic surfactant and block copolymer on carbon black particle surface charge and size. Colloids Surf. A: Physicochem. Eng. Aspects 2006, 278, 149-159. [CrossRef]

20. Miano, F.; Bailey, A.; Luckham, P.F.; Tadros, T.F. Adsorption of poly (ethylene oxide)—poly(propylene oxide) ABA block copolymers on carbon black and the rheology of the resulting dispersions. Colloids Surf. 1992, 69, 9-16. [CrossRef]

21. Pol, V.G.; Thackeray, M.M. Spherical carbon particles and carbon nanotubes prepared by autogenic reactions: Evaluation as anodes in lithium electrochemical cells. Energy Environ. Sci. 2011, 4, 1904-1912. [CrossRef]

22. Koprinarov, N.; Konstantinova, M. Preparation of carbon spheres by low-temperature pyrolysis of cyclic hydrocarbons. J. Mater. Sci. 2011, 46, 1494-1501. [CrossRef]

23. Meissner, T.; Oelschlagel, K.; Potthoff, A. Implications of the stability behavior of zinc oxide nanoparticles for toxicological studies. Int. Nano Lett. 2014, 4, 116-129. [CrossRef]

24. Szleifer, I.; Yerushalmi-Rozen, R. Polymers and carbon nanotubes-dimensionality, interactions and nanotechnology. Polymer 2005, 46, 7803-7818. [CrossRef] 
25. Hai, C.; Fuji, M.; Watanabe, H.; Wang, F.; Shirai, T.; Takahashi, M. Evaluation of surfactant-free stabilized vapor grown carbon fibers with $\zeta$-potential and Raman spectroscopy. Colloids Surf. A: Physicochem. Eng. Aspects 2011, 381, 70-73. [CrossRef]

26. Barany, S.; Kartel, N.; Meszaros, R. Electrokinetic Potential of Multilayer Carbon Nanotubes in Aqueous Solutions of Electrolytes and Surfactants. Colloid J. 2014, 76, 509-513. [CrossRef]

27. Park, Y.H.; Kim, W.S.; Lee, D.W. Size analysis of industrial carbon blacks by sedimentation and flow field-flow fractionation. Anal. Bioanal. Chem. 2003, 375, 489-495. [CrossRef]

28. Lau, A.C.; Furlong, D.N.; Healy, T.W.; Grieser, F. The electrokinetic properties of carbon black and graphitized carbon black aqueous colloids. Colloids Surf. A Physicochem. Eng. Aspects 1986, 18, 93-104. [CrossRef]

29. Boshkov, N.; Tsvetkova, N.; Petrov, P.; Koleva, D.; Petrov, K.; Avdeev, G.; Tsvetanov, C.; Raichevski, G.; Raicheff, R. Corrosion behavior and protective ability of $\mathrm{Zn}$ and $\mathrm{Zn}$-Co electrodeposits with embedded polymeric nanoparticles. Appl. Surf. Sci. 2008, 254, 5618-5625. [CrossRef]

30. Koleva, D.A.; Taheri, P.; Tsvetkova, N.; Boshkov, N.; Van Breugel, K.; De Wit, J.H.W.; Mol, J.M.C. Corrosion performance of composite galvanic coatings with variable concentration of polymeric nanoaggregates and/or Cr (III) conversion layers. ECS Trans. 2011, 33, 85-92. [CrossRef]

(C) 2020 by the authors. Licensee MDPI, Basel, Switzerland. This article is an open access article distributed under the terms and conditions of the Creative Commons Attribution (CC BY) license (http://creativecommons.org/licenses/by/4.0/). 